\title{
Large-scale innovation and change in UK higher education
}

\author{
Stephen Brown* \\ Faculty of Art, Design and Humanities, De Montfort University, Leicester, UK; Centre for \\ Distance Education, University of London International Programmes, London, UK
}

\begin{abstract}
This paper reflects on challenges universities face as they respond to change. It reviews current theories and models of change management, discusses why universities are particularly difficult environments in which to achieve large scale, lasting change and reports on a recent attempt by the UK JISC to enable a range of UK universities to employ technology to deliver such changes. Key lessons that emerged from these experiences are reviewed covering themes of pervasiveness, unofficial systems, project creep, opposition, pressure to deliver, personnel changes and technology issues. The paper argues that collaborative approaches to project management offer greater prospects of effective large-scale change in universities than either management-driven top-down or more champion-led bottom-up methods. It also argues that while some diminution of control over project outcomes is inherent in this approach, this is outweighed by potential benefits of lasting and widespread adoption of agreed changes.
\end{abstract}

Keywords: change management; top-down; bottom-up; distributive; leadership; innovation; collaboration; participation; participatory design; curriculum design; institutional practice; large scale; evolving culture; JISC; stakeholder

\section{Introduction}

"The management of change [in universities] is perhaps the most daunting challenge facing senior managers in organizations today" (McMurray 2001, p. 74), yet universities are peculiarly resistant to change (Marshall 2010). While some suggest that successful change can be planned and implemented through systematic, iterative processes (Burke and Litwin 1992), others argue that the environment within which organisations operate is so turbulent and reactive that linear models of cause and effect no longer apply, if they ever did (McMurray 2001; Stacey 1996). The reality is unpredictability, instability, irregularity, difference and disorder.

Keppel et al. (2010) observe how successful transformative change projects entail building shared vision and culture. The UK Learning and Teaching Support Network (LTSN) "Guidelines for Promoting and Facilitating Change" suggested that universities, for all their differences, tend to share the same culture, comprising:

- The sector's general commitment to collegiality.

- Fuzzy lines of accountability, particularly for academic staff.

- A general lack of extrinsic rewards to shape behaviour.

\footnotetext{
*Email: sbrown@dmu.ac.uk

RLT 2013. (C) 2013 S. Brown. Research in Learning Technology is the journal of the Association for Learning Technology (ALT), a UK-based professional and scholarly society and membership organisation. ALT is registered charity number 1063519. http:// www.alt.ac.uk/. This is an Open Access article distributed under the terms of the Creative Commons Attribution 3.0 Unported (CC BY 3.0) Licence (http://creativecommons.org/licenses/by/3.0/) permitting use, reuse, distribution and transmission, and reproduction in any medium, provided the original work is properly cited. 
- Well-developed subject sub-cultures.

- Rotating management and leadership responsibilities (in some contexts).

Within such a culture:

- Ability to influence is as important as authority to control.

- Managing tends to be by consent and incrementalism.

- Decisions tend to be committee-based and generally consensual.

- The status of potential change agents is often derived from personal credibility and their standing in a subject community.

- High value is placed on dialogue and the legitimacy of critique.

Source: LTSN Guidelines for Promoting and Facilitating Change: 7. (http://www. heacademy.ac.uk/assets/documents/institutions/change_academy/id296_Promoting_ and_facilitating_change.pdf)

These characteristics help to explain why universities are so resistant to change.

\section{Change management approaches}

Change management can be "top-down" (driven by management) or "bottom-up" (reflecting emergent or participatory-driven change) (Dearlove 1997). Top-down approaches tend to work where outcomes can be predicted with confidence and there is consensus about what those outcomes should be. Top-down approaches can run into opposition if staff do not agree with proposed changes and have sufficient independence to be able to resist them.

Bottom-up initiatives are generally generated by small groups of "early adopters" led by innovative individuals (Dearlove 1997). They often struggle to achieve the critical mass necessary for widespread adoption (Brown 2002; Marshall 2010; Rogers 2010). Thus, "the answer to large-scale reform is not to try to emulate the characteristics of the minority who are getting somewhere under present conditions .... Rather we must change existing conditions so that it is normal and possible for a majority of people to move forward" (Fullan 2001).

Keppel et al. (2010) suggest an alternative approach, "distributive leadership", in which change is jointly managed by more or less equal participants or "stakeholders" (Argyris 1999; Fullan 1993; Vidgen 1997). The list of potential stakeholders in a university is extensive. Figure 1 shows a preliminary map of stakeholders drawn up by a project reported here.

Figure 2 shows a taxonomy of engagement levels ranging from the most superficial (telling people what is going to be done to them) to inviting them to define the problem in their own terms and encouraging them to develop and implement their own solutions.

The range is thus from completely prescriptive "top-down", through more participatory to completely uncontrolled "bottom-up" approaches. Top-down tends to be efficient in terms of time and resource management and control over project outputs (reports, IT systems, procedures, and so on). However, it does not necessarily guarantee adequate control over outcomes (how people use those outputs and how 


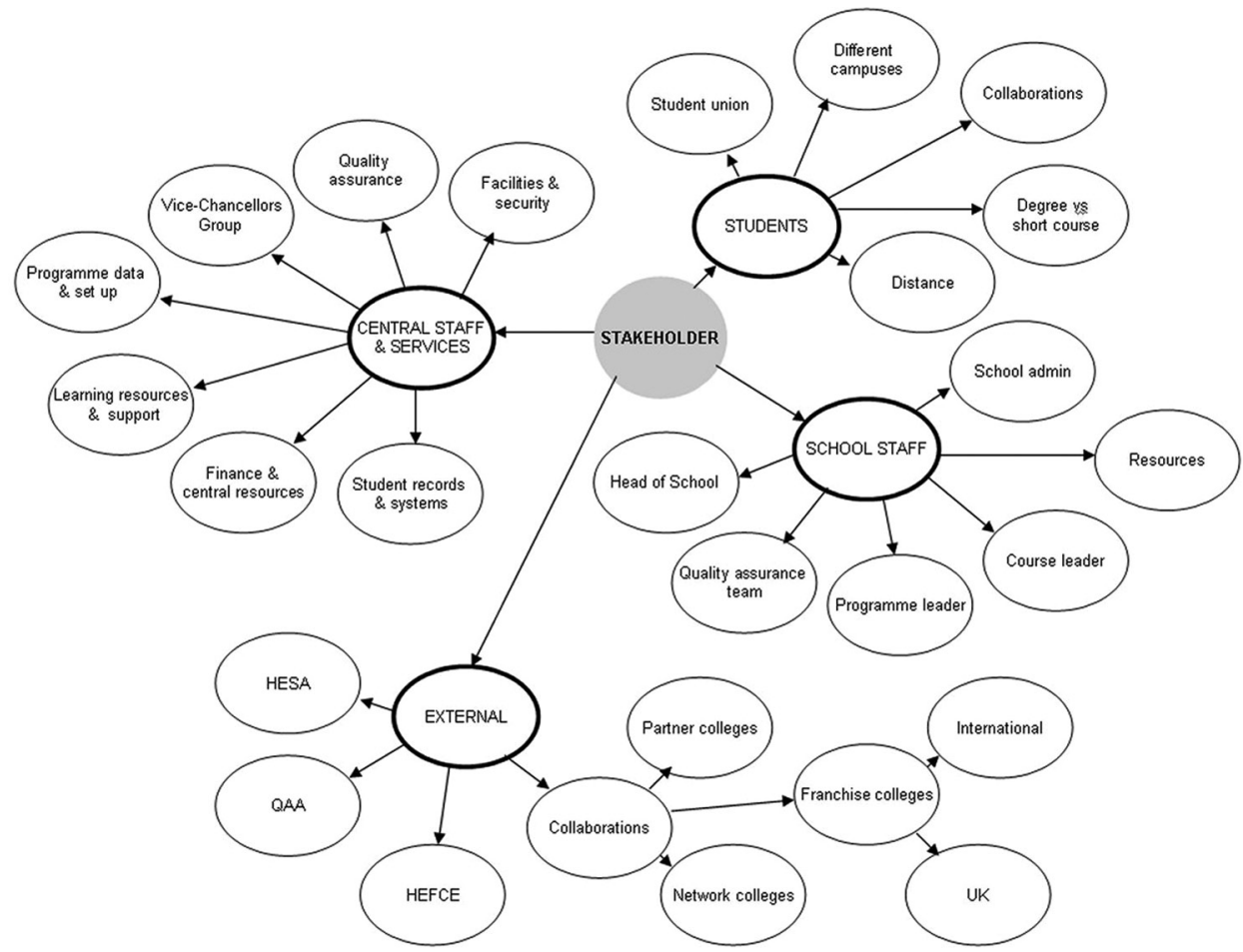

Figure 1. A map of potential university stakeholders. Source: UG-FLEX Project Plan v1_3 06/02/09 University of Greenwich. Reproduced with permission.

they feel about them). A tightly controlled project that produces a technically workable solution on time and to budget may run into implementation and sustainability problems if key stakeholders feel aggrieved about lack of involvement and do not believe the solution meets their needs. At the other end of the spectrum, project outputs produced by localised initiatives are likely to be enthusiastically supported by their progenitors but largely ignored by the rest of the institution. Projects intended to achieve outcomes that are workable and sustainable across the institution are more likely to succeed if they tread a path somewhere between these extremes.

\section{The Curriculum Design and Delivery experiment}

The JISC Curriculum Design and Delivery programmes (http://www.jiscinfonet.ac.uk/ curriculum) comprised 27 projects that explored how technology can help address major curriculum challenges. Grouped into two strands, Curriculum Design projects ran for 4 years (2008-2012) and Curriculum Delivery projects for 2 years (2008-2010). They are possibly the largest experiments in change management and innovation in UK higher education so far. Design Cluster B in the Curriculum Design strand, on which this paper focuses, included Birmingham City University, City University London, Cardiff University, Cambridge University and Greenwich University. 


\begin{tabular}{|c|c|c|c|c|c|c|}
\hline \multirow{3}{*}{ 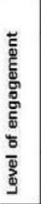 } & Notify & Inform & Consult & Involve & Collaborate & Empower \\
\hline & $\begin{array}{l}\text { Stakeholder s may } \\
\text { enowunter untargeted } \\
\text { project publicity }\end{array}$ & $\begin{array}{l}\text { Stakeholders are } \\
\text { regularly and reliably } \\
\text { informed, made aware } \\
\text { of their rights and } \\
\text { ways of partiopating } \\
\text { in the project }\end{array}$ & $\begin{array}{l}\text { Project staff obtain views } \\
\text { of stakeholders. } \\
\text { Stakeholders receive full } \\
\text { feedback on decisions } \\
\text { taken }\end{array}$ & $\begin{array}{l}\text { Project staff work with } \\
\text { stakeholders throughout } \\
\text { decision making process to } \\
\text { ensure views are } \\
\text { understood and taken into } \\
\text { account }\end{array}$ & $\begin{array}{l}\text { All aspects of decision } \\
\text { making processes are } \\
\text { undertaken in partnership } \\
\text { with stakeholders }\end{array}$ & $\begin{array}{l}\text { Stakeholders set agendas } \\
\text { for change. Self } \\
\text { organisation and } \\
\text { responsibility over } \\
\text { management is held by } \\
\text { stakeholders }\end{array}$ \\
\hline & $\begin{array}{l}\text { Information made } \\
\text { available }\end{array}$ & Stakeholders informed & Stakeholder consulted & Stakeholder input & Stakeholder shaped & Stakeholder owned \\
\hline 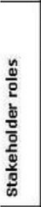 & $\begin{array}{l}\text { Stakeholders as } \\
\text { passive recipients of } \\
\text { uncontextualised } \\
\text { inform ation } \\
\text { Dialogue with project } \\
\text { staff is not expected }\end{array}$ & $\begin{array}{l}\text { Stakeholders as } \\
\text { passive recipients of } \\
\text { broadly contextualised } \\
\text { information } \\
\text { Dialogue with project } \\
\text { staff is implic tly } \\
\text { welcomed but not } \\
\text { explicitly invited }\end{array}$ & $\begin{array}{l}\text { Stakeholders as } \\
\text { respondents } \\
\text { Designated consultation } \\
\text { space/time in meetings } \\
\text { Feedback/right of reply } \\
\text { strategies } \\
\text { Some dialogue with } \\
\text { project staff is expected }\end{array}$ & $\begin{array}{l}\text { Stakeholders as project } \\
\text { team members } \\
\text { Stakeholder appointment } \\
\text { on POG } \\
\text { Participation in skills } \\
\text { training }\end{array}$ & $\begin{array}{l}\text { Stakeholders as collaborators } \\
\text { Stakeholders on } \\
\text { m anagem ent com mittees } \\
\text { Stakeholder shaped policy } \\
\text { making } \\
\text { Stakeholder interest/action } \\
\text { groups }\end{array}$ & $\begin{array}{l}\text { Stakeholders as designers } \\
\text { (independent) } \\
\text { Distributed decision } \\
\text { making } \\
\text { Stakeholder managers } \\
\text { Stakeholder bownership' of } \\
\text { resources, events, polides } \\
\text { and learning }\end{array}$ \\
\hline 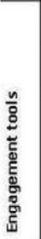 & $\begin{array}{l}\text { Untargeted publicty } \\
\text { Access to } \\
\text { minutes/docum ents } \\
\text { Static website }\end{array}$ & $\begin{array}{l}\text { Briefings } \\
\text { Regular blogs } \\
\text { Targeted letter }\end{array}$ & $\begin{array}{l}\text { Comment/opinion polls } \\
\text { Focus groups } \\
\text { (stakeholders as } \\
\text { respondents) } \\
\text { Project staff led } \\
\text { consultation workshops } \\
\text { Project staff led } \\
\text { questionnaires, } \\
\text { interviews }\end{array}$ & $\begin{array}{l}\text { Workshops } \\
\text { voting } \\
\text { Active focus groups } \\
\text { Joint-led consultations } \\
\text { Intervews (open-staff } \\
\text { directed) }\end{array}$ & $\begin{array}{l}\text { Stakeholder-led } \\
\text { consultations } \\
\text { Interviews open/dosed } \\
\text { (stakeholder directed) } \\
\text { Open forums } \\
\text { Rich picture activities } \\
\begin{array}{l}\text { Away days with } \\
\text { stakeholders and project } \\
\text { teams }\end{array}\end{array}$ & $\begin{array}{l}\text { Stakeholder managed } \\
\text { programmes } \\
\text { Stakeholder agenda } \\
\text { setting } \\
\text { Stakeholder managed } \\
\text { consultation activities and } \\
\text { todls development }\end{array}$ \\
\hline 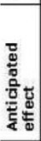 & $\begin{array}{l}\text { Potential for } \\
\text { peripheral general } \\
\text { awareness }\end{array}$ & $\begin{array}{l}\text { Potential for informed, } \\
\text { contextualised } \\
\text { awareness }\end{array}$ & $\begin{array}{l}\text { Confirmed widespread } \\
\text { contextualised awareness } \\
\text { Emergence of reaction } \\
\text { data }\end{array}$ & $\begin{array}{l}\text { Emergent reaction data is } \\
\text { not framed exdusively by } \\
\text { projedt staff } \\
\text { Stakeholder agendas are } \\
\text { collected and recogrised }\end{array}$ & $\begin{array}{l}\text { Agendas emerge only from } \\
\text { collaborative activity with } \\
\text { stakeholders }\end{array}$ & $\begin{array}{l}\text { New mechanisms are } \\
\text { established which are } \\
\text { stakeholder owned } \\
\text { Project is self-sustainable } \\
\text { with no expectation of } \\
\text { project team intervention }\end{array}$ \\
\hline
\end{tabular}

Adapted by Bartholomew, P., Freem an R $(2009,2010)$ as part of T-SPARC at Birmingham City University from 'Levels of learner voice participation' in 'Rudd, T., Colligan, F. and Naik, R. (2006) "Learner voice: a handbook from Futurelab". Bristol, Futurelab.

Figure 2. The ladder of engagement. Source: The Design Studio. http://jiscdesignstudio. pbworks.com/w/page/27046505/T-SPARC\%20Stakeholder\%20Engagement\%20Model (Accessed 02/01/2013). Reproduced with permission.

\section{Birmingham City University (T-SPARC)}

T-SPARC project goals were:

(1) Informing programme design processes by making available rich data, in electronic form, to course teams.

(2) Redesign of the ICT infrastructure and workflow of curriculum design and programme approval.

(3) Support for course design through facilitation of course team dialogue and sharing of resources by electronic means.

(4) Providing evidence of the design process and rationale for design decisions at the point of course approval.

The project team intended from the outset to work with all university staff with a role in the design or delivery of academic programmes in order to identify and map challenges to effective and efficient programme design and approval. The team envisaged that high levels of stakeholder participation would be achieved through deployment of appropriate technologies.

\section{City University, London (PREDICT)}

PREDICT at City University, London, aimed to develop a technology-supported process for undergraduate curriculum approval that facilitated interdisciplinary collaboration. The university's strategic plan had specified a need to reassess all programmes in order to identify: (1) programme fitness for purpose, (2) areas 
requiring further development, and (3) core competencies common to all curricula. A particular challenge was that traditional curriculum design was aligned to disciplinary boundaries, while the university expected to move to a more interdisciplinary curriculum, predicated on the growing consensus that interdisciplinary working is necessary to tackle real workplace problems that are complex, multidimensional and open ended. The university decided to develop a new curriculum design process not aligned to such boundaries and flexible enough to meet changing external and internal influences of diverse stakeholders - whether learners, staff or employers.

\section{University of Greenwich (UG-FLEX)}

UG-FLEX set out to analyse and model curriculum design and delivery models in use at Greenwich and to build on them to enable the university to significantly increase its part-time and flexible learning provision. On the agenda were Continuing Professional Development, Work-Based Learning and employer and community engagement, delivered via a mixture of methods (e-Learning, blended learning, workbased learning and face-to-face teaching) and of models (from long thin flexible parttime degrees to very short bite-size CPD courses). The primary focus was on specification of curriculum design and delivery models to support part-time and flexible study to:

- Re-engineer how curriculum structures, courses and programmes were represented within the student record system used to manage the admission and recruitment processes, track progression and provide a wide range of reports for relevant stakeholders.

- Review the implications for interactions between this system and other primary systems such as timetabling, virtual learning environments, library systems, financial and human resources systems.

- Open up discussion and debate about flexible provision and its implications for the multiple and diverse stakeholders and decision makers within and external to the university and the sector.

- Prepare staff and services to engage with the changes required to fully realise the vision of a truly flexible and agile higher education system.

\section{University of Cardiff (PALET)}

The PALET project intended to develop revised procedures for approval of new programmes, to create a more agile, efficient and flexible approach to the design of new curricula and the subsequent programme approval process. A service-oriented approach was envisaged to develop a toolset for academic and support staff through each stage of the new approval process, and to ensure that resulting programme and module information was clearly defined and could be seamlessly used by other business applications. PALET aimed to ensure that new programmes were attractive, innovative, market-relevant and of a high academic standard. It focussed on the business case developed for new programmes, the information required within a programme proposal and the process of curriculum design. The project was designed to draw upon tools being used across the university to support collaborative working and the development and management of online processes. It was also intended to 


\section{S. Brown}

link with work being undertaken to improve the university's data quality, to facilitate the most effective use of this data, and to improve the ability to find, access and publish corporate information. It was linked with several on-going university-wide projects including implementation of the Student Information Management System (SIMS) across the institution, review of the university's future approach to portfolio management, implementation of the university's learning, teaching and assessment strategies and a move towards a definitive single data source to cover the lifecycle of a programme from inception through to delivery. While PALET's success was not dependent on implementation of the related projects and initiatives, it was hoped that a holistic approach to policy and practice would help to transform institutional business processes over the short to medium term.

\section{Cambridge University (Course Tools)}

The overall project goal was to create an IT support process to make the curriculum design process better or easier to use. A primary target was reorganisation of the large Natural Sciences Tripos (NST). NST covers a wide range of departments and fields of undergraduate study, cross-departmental course sharing and students with annual subject changes, all of which creates significant timetabling complexity. CourseTools was envisaged in four phases:

- Review of current practices, negotiation of project objectives in the context of institutional drivers and detailed planning of project delivery.

- Technology support, to be introduced in phase 2 by shadowing departments that were introducing change using paper-based methods. The shadow team was to be composed of project team members and members of the departments concerned, and aimed to reproduce the paper processes using specific computer-based tools such as Kuali Student to demonstrate the technology's suitability and advantages of online working. During phase 2, training and support materials were to be prepared to support a technology-first phase 3 .

- In phase 3, departmental teams were to work with the new technology processes with "arms-length" support from the project team. CourseTools aimed to implement paper-based backup systems to reassure participating departments that there was little risk to their critical processes if new technology-led processes failed.

- Phase 4 was to pull together lessons learned and develop pilot integrations with other institutional IT systems.

In common with many universities' experience, major challenges faced by CourseTools included:

- A growing number of new courses and pressure to accommodate increased interdisciplinarity in courses.

- Increasing diversity in the student intake as a result of the widening participation agenda.

- The need to connect different institutional systems to provide a coordinated and coherent view of teaching and learning provision. These systems included student records, the human resources system, the collaboration and 
learning environment, a student supervision reporting system and a student feedback system.

In addition, CourseTools had to operate within the highly devolved organisational structure of Cambridge University.

Collectively these projects can be regarded as a microcosm of UK higher education, spanning a broad range of institutional types from "post 92" to "Russell Group", and addressing some of the biggest curriculum challenges, namely flexibility (UG-FLEX, PREDICT, CourseTools), employability (UG-FLEX, PREDICT), interdisciplinarity (PREDICT, CourseTools), coherent integration of curriculumrelated processes and systems (CourseTools, T-SPARC, PALET), agile development processes (T-SPARC, PALET) and transparent, evidence-based curriculum planning (T-SPARC, PALET). All of them intended to deploy technology to make more effective use of existing systems and data, involve stakeholders more actively, render processes more transparent and deliver more flexible and efficient ways of working.

Although technology has been seen as both a driver and a facilitator for change in universities for many years, the reality has often not lived up to expectations (Bates 2001; Carr 2003; Chester 2006; Cuban 2001; DfES 2003; Oliver 2005). Recognising this, the Curriculum Design Programme differed from earlier experiments; importantly the focus was on:

- Technology to support curriculum design rather than pedagogical practice itself.

- Large-scale, institution-wide processes rather than isolated non-missioncritical experiments.

- Collaboration between institutions to achieve critical mass across the sector as a whole.

\section{Findings}

After 4 years, common themes emerged from the Design Cluster B projects:

\section{Pervasiveness}

All five projects began with plans emphasising technical systems development (a timetabling system, a course information digital repository, a course approval support system) and had been conceived by a relatively small number of individuals in each institution. An early requirement of JISC was that the projects should think about stakeholder engagement and produce a "baseline report" that described starting conditions for each project. Baseline reports included not only quantitative metrics such as numbers of students undertaking certain kinds of courses, length of time required to approve new courses, numbers of uneconomic courses, but also views of stakeholders about systems and processes targeted for revision by the projects. They revealed that systems the teams were dealing with were more complex and interconnected than previously realised and that consequently the impact of changes would be more far-reaching. Figure 3 shows a collective effort by the five projects to describe the institutional context of the curriculum design and approvals process. It clearly illustrates the process's pervasiveness and the complexity of interactions between the stakeholders. 


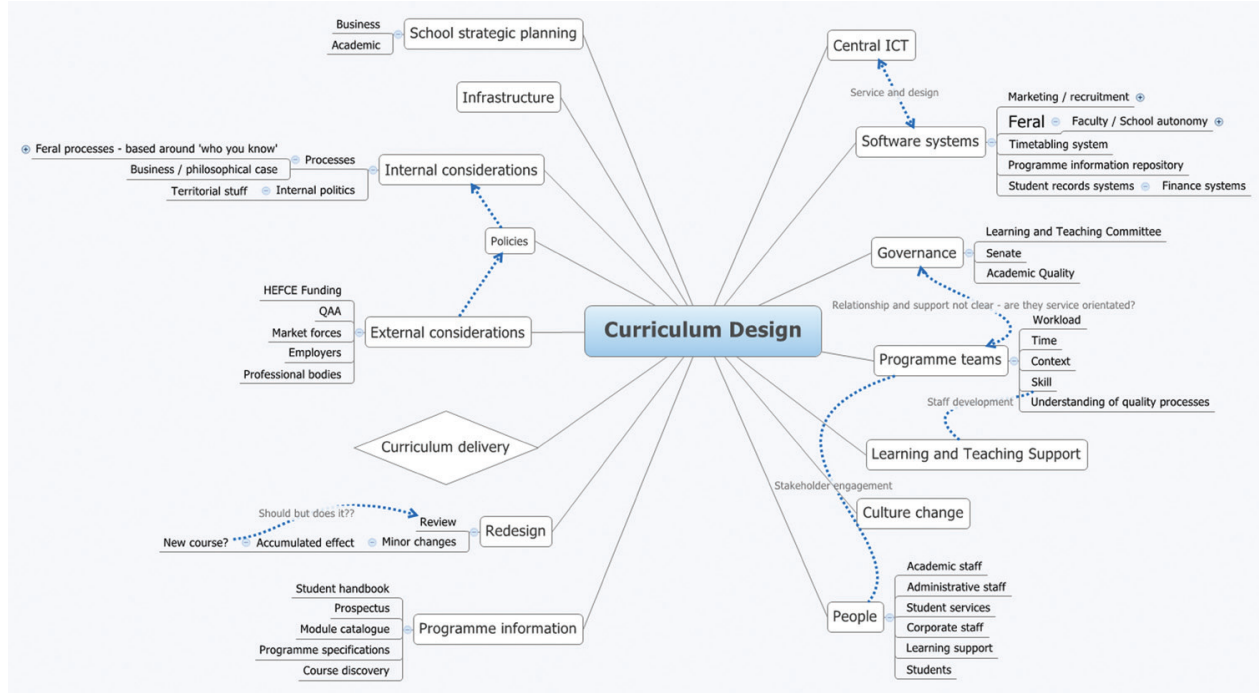

Figure 3. An overview of the institutional context of the curriculum design and approvals process. Source: Author.

Realisation that the scale of change required was greater than originally envisaged is not a completely new insight (Buchan 2011; Keppel et al. 2010) but one that had a direct effect on project timescales and plans and in some cases relationships between the project teams and other key stakeholders.

\section{Unofficial procedures and systems}

The baseline activity also revealed the existence of workarounds or unofficial procedures to make formal systems and processes work or to bend them to local needs and preferences.

School-based shadow IT [systems] referred to by some as 'feral systems' were the norm rather than the exception - a situation that was tacitly accepted by many as part and parcel of the highly devolved organisational model. (Eustace 2012, p. 4)

Evidence of unofficial systems brought home the need to think about how new systems and applications would be received by their intended users and to engage them in formulating problems as well as developing solutions. The value of stakeholder engagement in problem definition is a well-known phenomenon: "Organisations comprise subgroups that already have significant cultural momentum before any intervention begins. Design based interventions take into account how new designs are resisted, appropriated or even repurposed by such groups" (Bell 2004, p. 249). Again the consequences were felt in the project plans and timescales as these were adjusted to shift the projects more towards the participatory and collaborative end of the ladder of stakeholder engagement.

\section{Project creep}

As colleagues became more aware of the projects, problems they were trying to address and resources at their disposal, there was a tendency for institutions to ask or 
expect the projects to widen their briefs to take in more aspects of the university. This project creep followed on from the essential interconnectedness of the organisations and the pervasiveness of the systems they were working with. To maintain credibility and goodwill, projects were obliged to enlarge their remits and set aside prescriptive plans.

We feel that the fluidity afforded by our approach to project management has contributed to our credibility with stakeholders and, as a consequence, our ability to influence institutional agendas. (Bartholomew 2010, p. 17)

\title{
Opposition
}

Project creep can be regarded as a measure of success, but the downside is that it places greater demands on project resources. Also, in three projects, opposition was generated by a growing realisation among other stakeholders that the project outputs were likely to impinge on their own operations. This realisation was so strong in some instances that the projects felt it necessary to adopt a "submarine" approach in order to diffuse tensions, working from behind the scenes through other agencies. Accommodating different stakeholder perspectives, sometimes conflicting ones, is critical in large-scale change management projects (Gunn 2010).

\begin{abstract}
A lesson here is very much about the need to be responsive to the institutional priorities and changes and not try to gain engagement in a project that would be seen to be out of step with this. This does mean making the project appeal to a wide range of people and there is a need to make the benefits to them engaging clear. These may be different in a range of stakeholders and the project needs to have the flexibility to permit this to happen. (Parker and Quinsee 2010, p. 10)
\end{abstract}

\section{Pressure to deliver}

The original project bid plans reflected their technological focus. While risk registers had been drawn up and contingency plans made, some stakeholders were not well prepared for the discovery that systems and processes were more pervasive, that change would need to be more widespread and that more time was required to engage stakeholders in a more inclusive and participatory manner than originally anticipated. Three projects came under pressure to proceed without delay to solution building and implementation. It became a major challenge to convince stakeholders of the need to hold off from delivery of technical solutions in order to develop the cultural readiness required to implement them.

It is far easier to change policy and implement technical innovations than it is to bring about cultural changes. (Jenkins et al. 2011, p. 448)

The T-SPARC project encapsulates the lesson learned from these experiences:

At the start of the project, the development of a formal Project Initiation Document and a push from the JISC towards waterfall methods of project management (such as PRINCE2) offered a useful opening structure to begin work and to produce an initial shared framework for collaboration with CICT. However, after a fairly short time, this way of working became too restrictive - the expectation to declare dates, identify prerequisite activities and develop 'work packages' was not well-aligned with the needs of a project that was trying to deliver against a continually emerging set of requirements from our stakeholder groups. (Bartholomew 2012, p. 12) 


\section{S. Brown}

\section{Personnel changes}

Roche observed that less than 3 years appears to be insufficient to achieve large-scale change (2001, p. 121). The Curriculum Design projects lasted for 4 years. While this gave them more time to get things right, it allowed more opportunities for problems to emerge. For example, all the projects experienced loss of key personnel for various reasons. This was most acute at Cambridge where, uniquely in the Cluster, CourseTools was situated in a self-funding research unit rather than a service function. Staff were employed on fixed term contracts, and there was a higher level of churn than experienced by the other projects. CourseTools managers moved on so often (four times in as many years) the project was unable to develop sufficient momentum and was terminated. All five of the institutions experienced change at Pro Vice Chancellor level or above. Strategic leaders can only achieve transformative change when they have a political power base in the university environment (Roche 2001), and the departure of senior key stakeholders required projects to re-engage political support, in some cases shifting project goals as institutions revisited and revised their strategic priorities.

\section{Technology issues}

The projects were intended to deliver significant and sustainable changes to the way participating institutions used technology to enhance or support curriculum design. T-SPARC intended to redesign the ICT infrastructure that underpins the workflow of curriculum design and programme approval, using SharePoint 2010. The project team was dependent on collaboration with other university departments, including the IT support function (CICT). Although the project was able to develop an emergent specification to work to, it was a challenge to engage effectively with internal software developers in CICT. With hindsight, it was recognized that earlier and more structured engagement with CICT might have been beneficial.

At Cambridge, planned technical outputs were a deployment of Kuali Student LUM and accompanying documentation explaining its operation and configuration both for the university and the wider UKHEI community. The Kuali data structure was to be used to store information about courses, capable of supporting applications aimed at promoting curriculum flexibility and innovation, in particular workflows for a variety of course development and approval processes, and for timetable generation. Kuali development, which was not under the control of the CourseTools team, did not proceed as rapidly as expected, however, and plans for building a Student Information System based on it were not realised.

\section{Conclusions}

From the beginning, each of these institutions had identified major changes they needed to make and particular technologies they intended to employ in order to do so. By the projects' end, the higher education landscape had altered dramatically, affecting all universities in the UK to some degree. For many institutions, organisational change has been a necessary response to these developments, but changing universities is particularly hard because of university culture and the characteristics of the people who work in them. Top-down approaches are frequently resisted, and bottom-up initiatives tend to run into opposition as they scale up. 
However, change is possible. The Curriculum Design programme demonstrated how large-scale institutional projects can be run with varying degrees of success if certain conditions are met. These conditions include:

(1) Effective stakeholder engagement and ownership based on understanding and trust

(2) Participatory/collaborative definition of problems and solutions

(3) In-depth understanding of context and issues before development of solutions irrespective of project timelines

(4) Subjugation of technology to stakeholder requirements and the user experience.

The jury is still out on these projects in as much as it will take some years for the innovations they developed to become embedded in the normal processes of their institutions. It is still possible that, like other projects before them, they will be only short-lived successes. However, as funding came to an end for the four surviving Design Cluster B projects, the signs were encouraging. T-SPARC delivered a system and process that successfully addressed all of the project aims; PREDICT was successful in changing the institutional culture around curriculum; PALET did create a new, holistic context for how Cardiff University approaches the design, management and communication of its educational provision in the future; UG-FLEX played a significant role in developing a more complete understanding of the concept and consequences of curriculum flexibility and the impact on processes and digital systems. It also delivered significant enhancements to the management of information at the University of Greenwich. While CourseTools was unable to realise its ambitious goals in full, it nevertheless managed to create new sources for key information related to courses that could significantly enhance the availability, discoverability and coherence of online course information in future: searchable online timetable data and searchable online access to exam questions.

One final point remains to be considered. The experiences reported here support the view that participatory design and distributive leadership approaches are effective delivery strategies for institutional-wide change in universities. However, one possible implication of this approach is less control over project outcomes. Logically, if stakeholders have more say in defining the problems and developing the solutions, then they may come up with ideas that are different from those in the original project conception. How much does this matter? The answer probably depends on what those outcomes are and the overall context. It may be difficult to persuade an external funder to change direction, for example. The issue here is risk. Something that, although not originally envisaged, is widely regarded as appropriate and worthwhile because it is owned by the majority who played a part in creating it may be less risky in the long term than a system rejected by a significant proportion of stakeholders, that makes them feel disempowered and which spawns numerous "feral" alternatives. Universities are peculiarly resistant to change but in a rapidly changing, increasingly turbulent and unpredictable world, capacity for real change is essential. Empowering stakeholders to take control of their future may sound a bit like flying blind, but it is probably preferable in the long run to flying in the wrong direction. 


\section{S. Brown}

\section{Acknowledgements}

The projects described here were funded by JISC's Curriculum Design programme. Thanks are due to JISC's programme and support teams and to the project teams for permission to report this work.

\section{References}

Argyris, C. (1999) On Organzational Learning, 2nd edn, Blackwell, Cambridge, MA.

Bartholomew, P. \& Freeman, R. (2009, 2010) The ladder of engagement. Adapted from 'Levels of learner voice participation' in Rudd, T, Colligan, F., Naik, R. (2006) Learner Voice: A Handbook from FutureLab, FutureLab, Britsol. Source: The Design Studio. http:// jiscdesignstudio.pbworks.com/w/page/27046505/T-SPARC\%20Stakeholder\%20Engagement $\% 20$ Model.

Bartholomew, P. (2010) T-SPARC Interim Report, Birmingham City University, Birmingham.

Bartholomew, P. (2012) The T-SPARC Institutional Story (Final Report), Birmingham City University, Birmingham. Source: The Design Studio. http://jiscdesignstudio.pbworks.com/ w/file/fetch/59091253/Curriculum\%20Design\%20Institutional\%20Story\%20-020BCU.pdf

Bates, A. W. (2001) 'The continuing evolution of ICT capacity: the implications for education', in The Changing Face of Virtual Education, ed G. M. Farrell, The Commonwealth of Learning, Vancouver, pp. 29-46.

Bell, P. (2004) 'On the theoretical breadth of design-based research', Educational Psychologist, vol. 39, no. 4, pp. 242-253.

Brown, S. (2002) 'Re-engineering the University', Open Learning, vol. 17, no. 3, pp. 231-243.

Buchan, J. F. (2011) 'The chicken or the egg? Investigating the transformational impact of learning technology', Research in Learning Technology, vol. 19, no. 2, pp. 155-172.

Burke, W. W. \& Litwin, G. H. (1992) 'A causal model of organizational performance and change', Journal of Management, vol. 18, no. 3, pp. 523-545.

Carr, N. (2003) 'IT doesn't matter', Harvard Business Review, vol. 81, no. 5, pp. 5-12.

Chester, T. M. (2006) 'A roadmap for IT leadership and the next ten years', Educause Quarterly, p. 29. [online] Available at: http://www.educause.edu/apps/eq/eqm06/eqm0626.asp

Cuban, L. (2001) Oversold and Underused: Computers in the Classroom, Harvard University Press, Cambridge, MA.

Dearlove, J. (1997) 'The academic labour process: from collegiality and professionalism to manageralism and proletarianism?' The Higher Education Review, vol. 1, pp. 56.

DfES. (2003) Towards a unified e-learning strategy, Department for Education and Skills, London.

Eustace, C. (2012) UG-FLEX Final Report. University of Greenwich, London. Source: The Design Studio. http://jiscdesignstudio.pbworks.com/w/file/59199984/Curriculum\%20Design $\% 20$ Institutional $\% 20$ Story $\% 20-\% 20$ Greenwich.pdf

Fullan, M. (1993) Change Forces, Falmer Press, London.

Fullan, M. (2001) The New Meaning of Educational Change, Teachers College Press, New York.

Gunn, C. (2010) 'Sustainability factors for e-learning initiatives', ALT-J: Research in Learning Technology, vol. 18, no. 2, pp. 89-103.

Jenkins, M., et al. (2011) 'The development of technology enhanced learning: findings from a 2008 survey of UK higher education institutions', Interactive Learning Environments, vol. 19, no. 1, pp. 447-465.

Keppel, M., et al. (2010) 'Transforming distance education curricula through distributive leadership', ALT-J: Research in Learning Technology, vol. 18, no. 3, pp. 165-178.

Marshall, S. (2010) 'Change, technology and higher education: are universities capable of organisational change?', ALT-J: Research in Learning Technology, vol. 18, no. 3, pp. 179-192.

McMurray, D. W. (2001) 'The importance of "goodness of fit" between organisational culture and climate in the management of change: a case study in the development of online learning', ALT-J: Research in Learning Technology, vol. 9, no. 1, pp. 73-83.

Oliver, R. (2005) 'Ten more years of educational technologies in education: how far have we travelled?', Australian Educational Computing, vol. 20, no. 1, pp. 18-23.

Parker, P. \& Quinsee, S. (2010) PREDICT Interim Report, City University, London. 
Roche, V. (2001) 'Professional development models and transformative change: a case study of indicators of effective practice in higher education', The International Journal for academic development, vol. 6, no. 2, pp. 121-129.

Rogers, E. M. (2010) The Diffusion of Innovations, 4th edn, John Wiley and Sons, New York.

Rudd, T, Colligan, F. \& Naik, R. (2006) Learner Voice: A Handbook from FutureLab, FutureLab, Bristol.

Stacey, R. (1996) Strategic Management and Organisational Dynamics, 2nd edn, Pitman, London.

Vidgen, R. (1997) 'Stakeholders, soft systems and technology: separation and mediation in the analysis of information system requirements', Information Systems Journal, vol. 7, no. 1, pp. 21-46. 